\title{
36 Strengths-based approaches for assessing student wellbeing
}

\author{
Jennica Paz, Katina Lambros, and \\ Shameeka Lewis
}

\section{How to use this policy}

"Strengths-based approaches for assessing student wellbeing" is a best practice policy that highlights how schools can focus on the assessment of student strengths and assets to build upon core social-emotional competencies that are foundational for educational success. Following a public health perspective for assessing wellbeing, a comprehensive, team-oriented, strengths-based approach should be considered. Ideally, this approach is implemented collaboratively, with input from stakeholders committed to incorporating comprehensive wellbeing indicators in the assessment process. Outcome data should be linked with tiered levels of supports related to positive psychological interventions that boost wellbeing of all students. The inclusion of standardized assessments of youth strengths provides critical information regarding assets and resiliency factors that should be intentionally incorporated into service planning. This is important, especially for students with or at risk for disabilities or diagnoses stemming from traditional deficit-based approaches assessing risks and symptoms. A strengths-based approach to assessment is necessary for use with Black, Indigenous, People of Color (BIPOC) and youth with long-standing histories of discriminatory referral and assessment practices. Schools can use this policy in conjunction with others, to begin dismantling unjust assessment practices leading to disproportionate representation of BIPOC youth in exclusionary settings and underrepresentation in gifted and accelerated programs. This policy is intentionally broad and school policy creators are encouraged to delete and build upon suggestions below to create a policy that best represents their school.

Multitiered Systems of Support (MTSS) and population-based models offer ideal frameworks for applying strength-based assessment and linking it to practices that emphasize strengths and wellbeing (Doll et al., 2014; Nickerson \& Fishman, 2013). Assessing mental health from multidimensional perspectives aligns well with public health and population-based frameworks of school-based mental health screenings (Dowdy et al., 2010). Strengths-Based Assessment (SBA) has benefits and scientific rationale when grounded in a sound conceptual framework that offers an understanding of the process and factors associated with quality of life outcomes among children and adolescents. 
SBA has broad benefits when used to monitor the psychosocial strengths of all students (universal services or Tier 1). The future of positive psychology assessment with children in schools - when used as part of a universal assessment model - has the potential to benefit the largest number of students (Paz et al., in press). Strengths-focused measures have the greatest utility when used to provide comprehensive information about the optimal psychosocial development of all students. SBA also promotes positive family-school collaboration. Parents have higher rates of meeting attendance and positive satisfaction with services when SBA protocols are utilized within educational programs (Cox, 2006).

The adoption of SBA should be based on: (a) a conceptual framework of positive psychosocial strengths; (b) feasibility and utility as a school-based universal screening measure (reasonable length and availability of self-report); and (c) evidence of compelling psychometric properties, including replicated validity and reliability.

[To adapt and use this policy, delete or modify the text as indicated]

\section{[INSERT name of school] Strengths-based approaches for assessing student wellbeing}

\section{Rationale}

For decades, standardized assessments have been traditionally static and focused on a unidimensional understanding of pathology and eligibility. Strengths-Based Assessment (SBA) is a paradigm shift that aims to transform the way we think about and use assessment tools in schools. Educators encounter a range of school problems including academic difficulties, disruptive behavior, peer conflicts, mental health, and school climate challenges, so the need for culturally responsive and SBA is critical for remediation in these areas. Schools are more familiar with academic/achievement assessment and identifying patterns of strengths and weaknesses in performance; assessing strengths in relation to student wellbeing may be less familiar as best practice. An alarming $66 \%$ of all students report one or more adverse experiences during their time in school (Gonzalez et al., 2016). Given that nearly $20 \%$ of students experience mental health challenges that are identified and treated within school settings (SAMHSA, 2016), the need for early identification and intervention is critical to mitigating escalation and crises.

Broadly, SBA is defined as, "the measurement of internal and external emotional and behavioral competencies that enhance one's ability to develop relationships, deal with stress, and promote optimal development" (Nickerson, 2007). Positive psychological researchers propel the paradigm shift away from deficit-based assessment by emphasizing the need for integrated mental health classification systems, such as Dual Factor Models (DFM) and Complete Mental Health assessments. Assessing adaptive and deficit indicators, especially with respect to the importance of integrating both spectrums, assists 
with early identification of psychological and behavioral strengths and difficulties (Greenspoon \& Saklofske, 2001; Suldo \& Shaffer, 2008). The need to simultaneously attend to the dialectical and integrative effects of distress and personal strengths has been readily established in recent literature (Moore et al., 2019; Smith et al., 2020). Attending to both positive and negative indicators of mental health and wellbeing show additive value in predicting students' attendance and achievement over time (Dougherty \& Sharkey, 2017). Youth thrive and flourish when they develop psychosocial strengths that promote positive, supportive day-to-day interactions with family, teachers, and peers (Furlong et al., 2020). We advocate for a holistic approach that examines strengths in combination rather than in isolation; that is, assessment of the integrative effects of the core components of positive psychosocial development (Lenzi et al., 2015).

Per United Nations Convention on the Rights of Children, it is fundamental that positive developmental frameworks based on the capacity for self-determination and decision-making are used to ensure worldwide human rights for children (Miller et al., 2014). As an ongoing chief public health concern, echoed frequently in the media, systematic procedures for capturing the multifaceted needs and associated strengths of students and families are critical to ensuring positive youth development.

\section{Purpose}

School personnel can follow a process for SBA advocacy and implementation to ensure that the recognition and enhancement of strengths are incorporated systematically into school services.

\section{Scope}

This policy concerns all school staff as a general procedure and school teams (e.g., problem-solving teams, multidisciplinary teams) that examine climate, behavioral, and academic performance data involved in decision making about school services. Ideally, this policy will apply in all tiers of assessment intervention as an intentional practice that informs resource allocation.

\section{Policy statement}

[INSERT name of school] employs the use of Universal Level: Comprehensive Well-Being Screeners.

At [INSERT name of school], our staff:

(A) Engage in initial and ongoing training to ensure the conceptual framework of positive educational paradigms is understood and utilized school-wide. 
(B) Conduct regular (i.e., biannual) and systematic monitoring of wellbeing to provide appropriately matched MTSS supports and interventions. Screening efforts should be conducted at the start of the academic year and again halfway through the year.

(C) Use assessment tools with psychometric properties that are generalizable with diverse, cross-national samples of children and adolescents (see further reading section for strengths-focused exemplar assessment models; Paz et al., in press).

[INSERT name of school] uses a strengths-based approach for assessment and measurement models at the targeted and intensive levels to identify individualized assessments of strengths.

Our school incorporates strength-focused measures as part of a targeted assessment (secondary - Tier 2) or individual psychoeducational assessment (tertiary level - Tier 3), which allows students with special needs to have their strengths identified and described in their Individualized Educational Plans (IEP). At our school, we incorporate SBA across a continuum of levels (e.g., parent-student conferences, student success team meetings, psychoeducational evaluations, etc.) to promote a positive preventative model that includes improved affect, attitudes, and beliefs expressed by parents and team members.

Our school recognizes that there are over 150 tools with acceptable psychometric properties that may be incorporated into SBA practices to assess an array of positive attributes (e.g., optimism, resilience, grit, hope, emotional intelligence; Simmons \& Lehmann, 2013). Within our school, we measure strength-focused constructs related to psychosocial wellbeing in order to highlight the value of student voice (Halliday, et al., 2019) and gain deeper understanding of life circumstances. In our school, the results yielded from SBA inform intervention recommendations and identify areas of strength to expand upon (Rashid \& Ostermann, 2009).

Our school makes decisions as to which measure to use depending on the purpose of assessment. We consider whether measures have established validity for our culturally and linguistically diverse population. In our school we reference best practice guides to support us with navigating measures that serve to enhance the social emotional learning competencies of youth, including the RAND Education Assessment Finder: Measuring Social, Emotional, and Academic Competencies Guide and the Center for Social Emotional Learning (CASEL) Assessment Guide (see links included in the Further Reading section at the end of this document).

At [INSERT name of school] we track the assessment-intervention process to assess the longitudinal impact with respect to referrals, tiered levels of support, progress monitoring, eligibility, and disciplinary outcomes. We disaggregate data for various groups (e.g., Dual Language Learners, BIPOC, foster youth, LGBTQIA+ youth) to shed light on patterns of inequities and allow for curricula tailoring and/or resource re-allocation. We continue to 
utilize and refine, as necessary, the interventions that produce positive outcomes for students.

At [INSERT name of school] we acknowledge the need for culturally affirming pedagogies and practices, which are essential when highlighting diverse student strengths and resiliency. In our school we understand that it is imperative to maximize the potential of our youth to thrive given the surges of moral and sociopolitical upheaval, publicized school shootings, global pandemics, and unapologetic activism among BIPOC voices. At our school we include correlates of psychosocial strengths specifically informed by cultural and linguistic differences as a way to give voice and agency to historically marginalized students (e.g., Brendtro et al. [2002] provides a culturally-affirming assessment-intervention framework based on Indigenous knowledge of a student's sense of belonging, mastery, independence, and generosity).

For students in our school navigating language fluency and traditional assessment (e.g., determination of how limited they are in English), we recognize that this perpetuates a deficit-based stigma regarding youth potential. Instead, our school seeks to transform the rhetoric we use and adopt affirming terminology, such as Dual Language Learners (DLL), which "recognizes learning the heritage language alongside or in sequence with English and validates the heritage language as an asset" (Robinson-Zañartu et al., 2019). At our school we celebrate cultural assets and expertise among students. In our school we aim to understand how different cultural assets contribute to student wellbeing by making conscious, intentional efforts to understand and affirm a family's cultural values and assets so that our student's strengths become clear and central.

At [INSERT name of school] we will follow specific suggestions for using SBA measures and frameworks at the school-wide, group, and individual levels to identify strengths, target areas for development, monitor progress towards goals, and review guidelines delineated in Nickerson and Fishman (2013). Additionally, we will utilize the following checklist to support with implementing this new SBA policy:

- Advocate with administrators and instructional leaders about why SBA is important

- Research and select tools for various assessment purposes (universal screening pre-assessment, diagnostic, etc.)

- Research and select tools and interventions for various cultural and linguistic groups to ensure culturally responsive pedagogies

- Develop implementation plans in conjunction with school decisionmaking teams

- Communicate action steps with key community stakeholders

- Develop data collection and evaluation methods

- Offer ongoing professional development for school professionals 
Further, at our school, we will reference detailed descriptions on how to conduct universal complete mental health screening within a school system utilizing the Social Emotional Health System (SEHS) and utilize the step-bystep implementation guide found in Moore et al. (2016).

Finally, as change agents at [INSERT name of school], we acknowledge that it is our responsibility to engage in meaningful policy change so that our youth can thrive. We will begin to shed layers of privileged ways of thinking and shift from biased views of assessing deficits and risks towards a commitment to honoring and cultivating positive psychological wellbeing and complete mental health for truly all generations to come.

\section{Rating of evidence base}

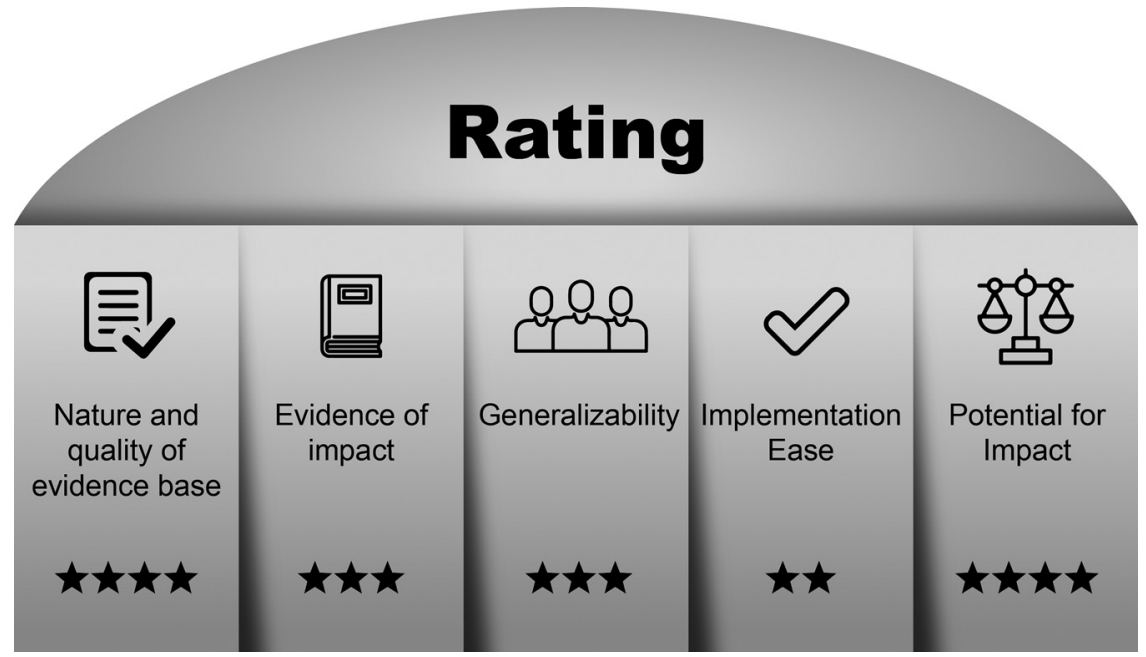

Figure 36.1 Strengths-Based Approaches for Assessing Student Well-Being Rating of Evidence.

Author Note. To our knowledge, we have not found studies with evidence of harmful or limited benefits of using SBA practices. Simply more research is needed across a variety of cultural groups and disability statuses. This policy has the potential to have high levels of positive impact, and this is demonstrated by case studies in articles cited. More work is needed to assess benefits at all MTSS levels. Much of the research supports generalizability across diverse groups of students around the globe. Depending on the selected SBA measures, there is more or less data available to support its applicability for certain groups of students. The ease of implementation will depend on several factors and will vary across schools. If schools already have an MTSS or school-wide surveillance/screening procedures in place, this will make the process smoother. Cost accrued would depend on measures selected and the feasibility of reports. The potential positive impact that may results from using SBA practices school-wide is very strong. Please review criteria discussed in the rationale section for outcomes and benefits of implementing SBA. 


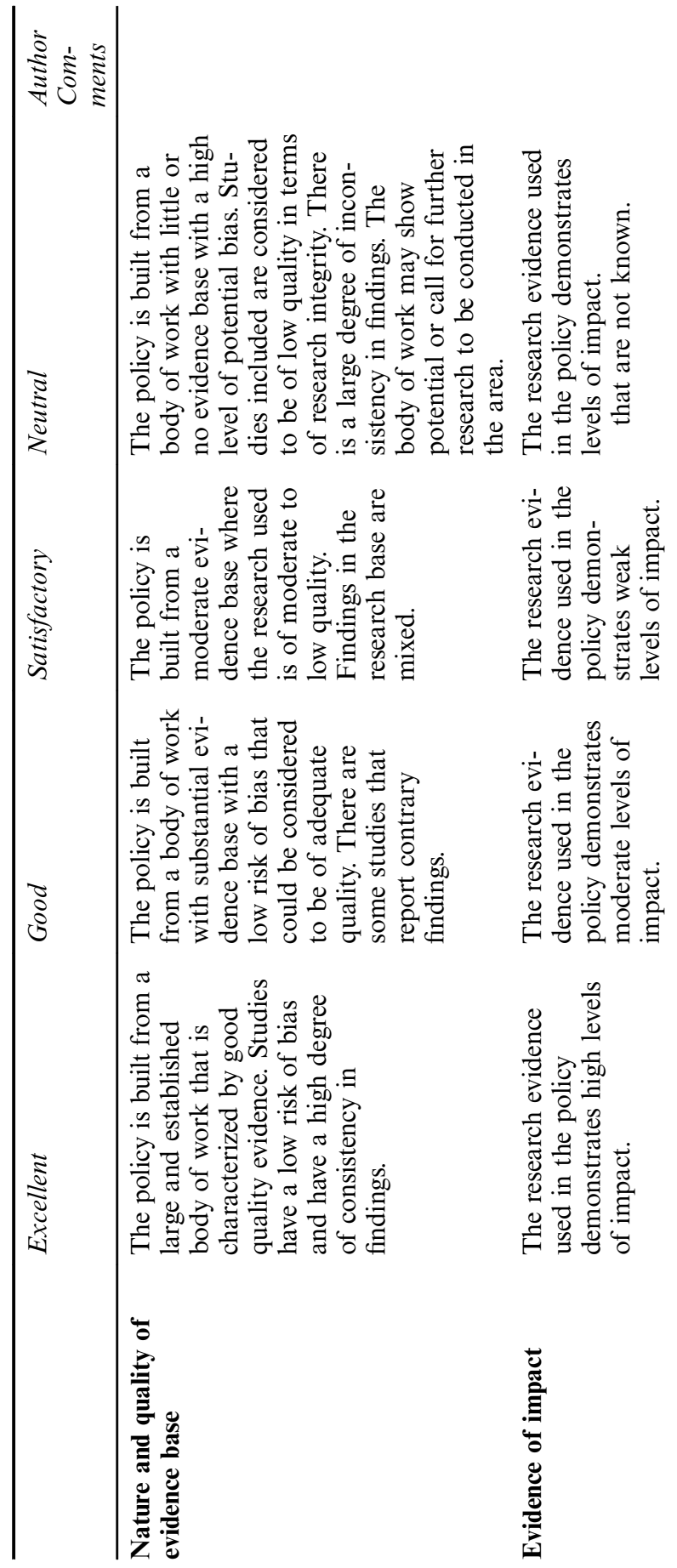



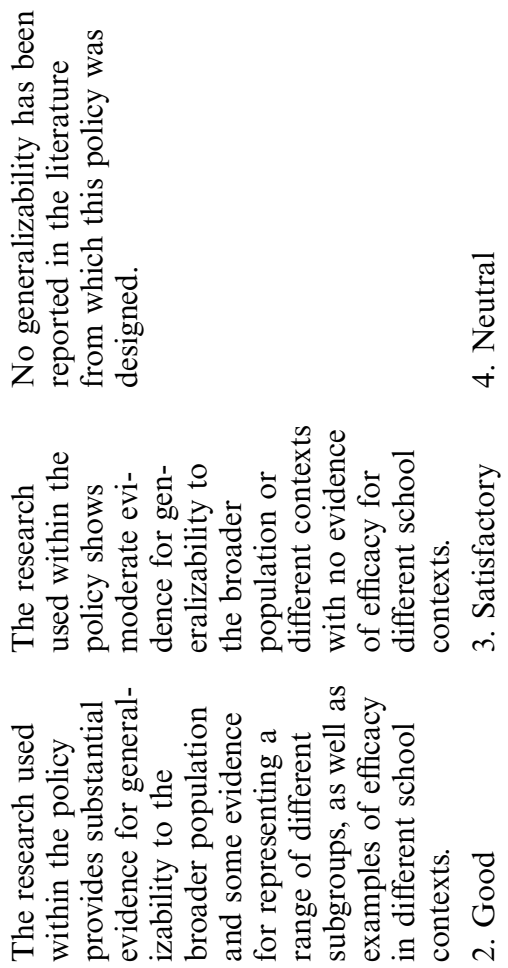

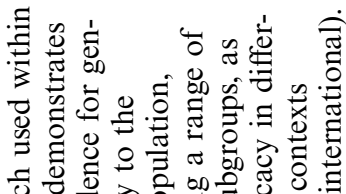
든

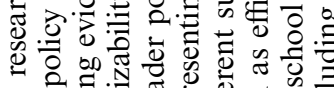

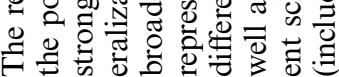

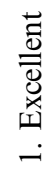

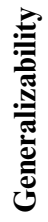

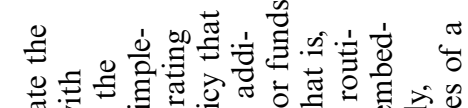
군

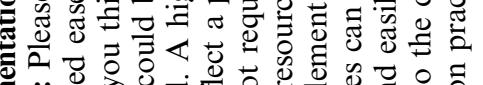

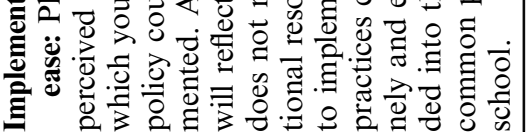




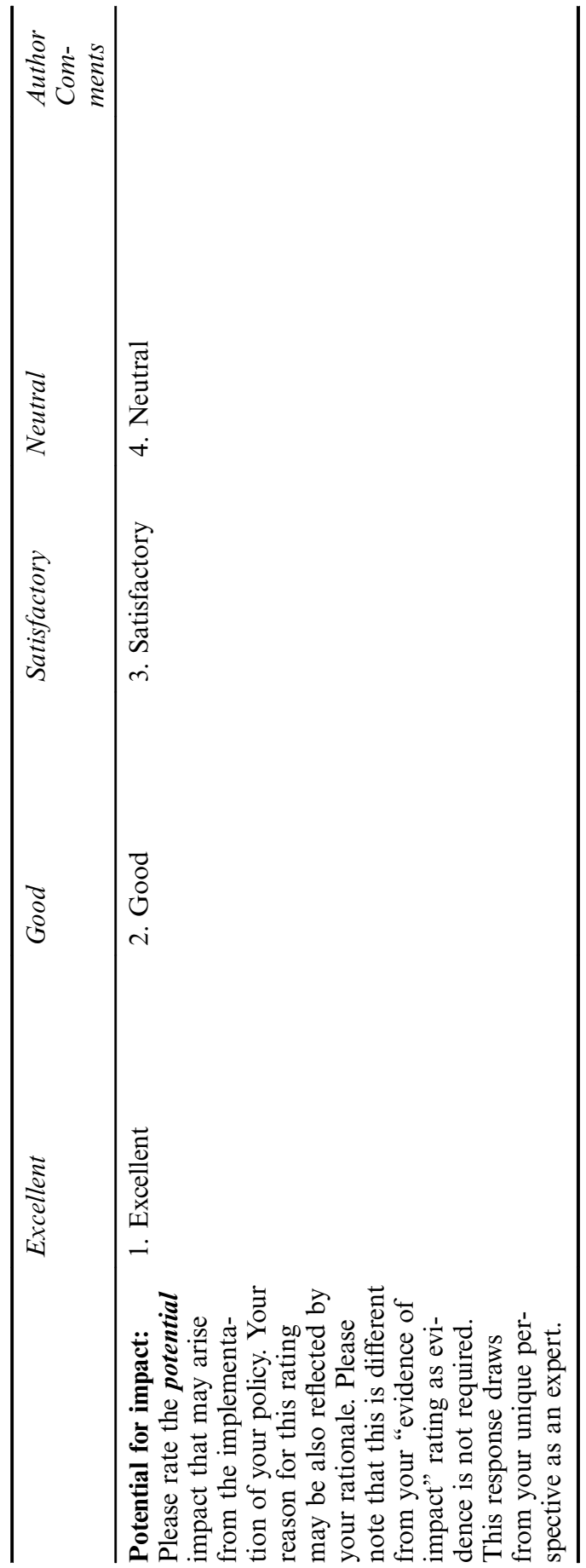




\section{Authorship}

Jennica Paz, PhD, LP, San Diego State University

Katina Lambros, PhD, BCBA-D, San Diego State University

Shameeka Lewis, EdS, San Diego State University

Department of Counselling and School Psychology

[INSERT RELEVANT STAFF MEMBERS]

\section{Related policy and documents}

\section{[INSERT RELEVANT POLICY AND DOCUMENTS]}

School trauma-informed practice

Mental health promotion

Data-based assessment of psychological well-being in whole school environments)

Included in this text are highly relevant and related information that would enhance and support the implementation of the SBA policies outlined in this Chapter.

\section{Date of ratification}

This policy was ratified on the [INSERT DATE].

\section{Date of review}

This policy will be reviewed by [INSERT DATE].

\section{Further reading}

Strengths-focused exemplar models include:

(a) Kern, Benson, Steinberg, and Steinberg's (2016) Engagement, Perseverance, Optimism, Connectedness, and Happiness (EPOCH) framework

(b) Furlong et al.'s (2014) Social-Emotional Health Survey System (Covitality framework)

(c) Search Institute's 40 Developmental Assets Framework

(d) Lerner et al.'s (2005) Five Cs framework of Positive Youth Development

International Center for School-Based Youth Development. (2020). Project covitality: Access to social emotional health survey system. https://www. covitalityucsb.info/index.html

Center for Social Emotional Learning [CASEL]. (2020). Measuring SEL: Using data to inspire practice. CASEL. https://measuringsel.casel.org/a ccess- assessment-guide/ 
Nickerson, A. B. (2007). The use and importance of strength-based assessment. School Psychology Forum: Research in Practice, 2(1), 15-25.

Moore, S. A., \& Widales-Benitez, O., \& Carnazzo, K. W., Kim, E. K., Moffa, K., $\&$ Dowdy, E. (2016). Conducting universal complete mental health screening via student self-report. Contemporary School Psychology, 19, 253-267.

Paz, J. L., Kim, E. K., Dowdy, E., Furlong, M. J., Hinton, T., Piqueras, J. A., Rodríguez-Jiménez, T., Marzo, J. C., \& Coats, S. (in press). Contemporary assessment of youth comprehensive psychosocial assets: School-based approaches and applications. In W. Ruch, A. Bakker, L. Tay, \& F. Gander (Eds.), Handbook of positive psychology assessment. Psychological assessment - Science and practice. European Association of Psychological Assessment.

\section{Expert consultation}

Ongoing consultation with a variety of key school stakeholders and community mental health partners is recommended to ensure efficacy and full benefits of an SBA practice.

\section{References}

Brendtro, L. K., Brokenleg, M., Bockern, S. V. (2002). Part II: The circle of courage. In Reclaiming youth at risk: Our hope for the future (pp. 43-59). Bloomington, IN: National Educational Service.

Cox, K. F. (2006). Investigating the impact of strength-based assessment on youth with emotional or behavioral disorders. Journal of Child \& Family Studies, 15(3), 278-292.

Doll, B., Cummings, J. A., \& Chapla, B. A. (2014). Best practices in population-based school mental health services. In P. Harrison \& A. Thomas (Eds.), Best practices in school psychology: Systems-level services (6th ed.). (pp. 149-164). Bethesda, MD: National Association for School Psychologists.

Dougherty, D., \& Sharkey, J. D. (2017). Reconnecting youth: Promoting emotional competence and social support to improve academic achievement. Children and Youth Services Review, 74, 28-34.

Dowdy, E., Ritchey, K., \& Kamphaus, R. W. (2010). School-based screening: A population-based approach to inform and monitor children's mental health needs. School Mental Health, 2, 166-176.

Furlong, M. J., Nylund-Gibson, K., Dowdy, E., Wagle, R., Hinton, T., \& Carter, D. (2020). Modification and standardization of social emotional health survey - Secondary - 2020 edition. Santa Barbara, CA: University of California Santa Barbara, International Center for School Based Youth Development.

Gonzalez, A., Monzon, N., Solis, D., Jaycox, L., \& Langley, A. K. (2016). Trauma exposure in elementary school children: Description of screening procedures, level of exposure, and stress symptoms. School Mental Health, 8, 77-88.

Greenspoon, P. J., \& Saklofske, D. H. (2001). Toward an integration of subjective wellbeing and psychopathology. Social Indicators Research, 54, 81-108. 
Halliday, A. J., Kern, M. L., Garrett, D. K., \& Turnbull, D. A. (2019). The student voice in well-being: A case study of participatory action research in positive education. Educational Action Research, 27, 173-196.

Lenzi, M., Dougherty, D., Furlong, M. J., Dowdy, E., \& Sharkey, J. D. (2015). The configuration protective model: Factors associated with adolescent behavioral and emotional problems. Journal of Applied Developmental Psychology, 38, 49-59.

Miller, G. E., Colebrook, J., \& Ellis, B. R. (2014). Advocating for the rights of the child through family-school collaboration. Journal of Educational \& Psychological Consultation, 24(1), 10-27.

Moore, S., Dowdy, E., Nylund-Gibson, K., \& Furlong, M. J. (2019). An empirical approach to complete mental health classification in adolescents. School Mental Health, 11, 438-453.

Nickerson, A. B., \& Fishman, C. E. (2013). Promoting mental health and resilience through strength-based assessment in US schools. Educational and Child Psychology, 30(4), 7-17.

Rashid, T., \& Ostermann, R. F. (2009). Strength-based assessment in clinical practice. Journal of Clinical Psychology, 65, 488-498.

Robinson-Zañartu, C., Draper, C., \& Olvera, P. (2019). White paper: The provision of school psychological services to dual language learners. Contemporary School Psychology, 23, 3-9.

Substance Abuse and Mental Health Services Administration [SAMHSA], Center for Behavioral Health Statistics and Quality. (2016). Key substance use and mental health indicators in the United States: Results from the 2015 national survey on drug use and health (HHS Publication No. SMA 16-4984, NSDUH Series H-51). http:// www.samhsa.gov/data/

Simmons, C. A., \& Lehmann, P. (2013). Tools for strengths-based assessment and evaluation. New York, NY: Springer Publishing Co.

Smith, N. D. W., Suldo, S. M., Hearon, B. V., Ferron, J. M. (2020). An application of the dual-factor model of mental health in elementary school children: examining academic engagement and social outcomes. Journal of Positive Psychology and Wellbeing, 4, 49-68.

Suldo, S. M., \& Shaffer, E. J. (2008). Looking beyond psychopathology: The dualfactor model of mental health in youth. School Psychology Review, 37, 52-68. 